\title{
EDITORIAL
}

\section{DERECHO Y CIENCIA: EL RECONOCIMIENTO DE LA INTERDISCIPLINA}

Desde hace bastante tiempo, juristas, académicos e investigadores del Derecho han reforzado la idea, que comparto, que el Derecho es una ciencia que tiene reglas de tal y que si bien no procede a su respecto el método empírico, implica un saber y una reflexión trascendente y no solo procedimientos o aplicaciones técnicas de la ley.

Sin embargo, la convicción que el Derecho es una ciencia no ha sido suficiente para instalar una segunda idea complementaria de la anterior: el reconocimiento de esta cualidad exige y demanda que el Derecho dialogue con otras ciencias y sea capaz de manifestarse adecuadamente en investigaciones que cultiven la interdisciplina tan necesaria en una gran cantidad de temas que, si bien son jurídicamente regulados y tratados, sin duda tienen sus raíces en otras fuentes y requieren conocimientos de muy variadas especies.

Esta pretensión ha sido harto más difícil de materializar. Las causas son multifactoriales, y solo para enumerar algunas trabas podemos considerar la diferencia de lenguajes y la dificultad de aunar conceptos; la resistencia de algunos científicos a descender a los campos regulatorios, y la de algunos abogados a tener que adquirir conceptos de otras ciencias; la imperatividad con la que muchos jueces creen que la ley lo resuelve todo, y la falta de una adecuada información, más que de contenidos, acerca de las razones por las cuales es indispensable contar con ella, más allá de la formación individual con la que cada uno puede contar.

Esta desconexión entre las ciencias, que nos ocupa a menudo, ha redundado en que existan aún en nuestro país temas no resueltos jurídicamente o que terminan siendo normados bajo supuestos inexistentes o incompletos; resolución de casos por nuestras cortes sin los debidos insumos; desinterés de nuestros legisladores respecto de procesos que concitan atención mundial, y una falta de colaboración en materias en que no solo se verían con buenos aportes de todos, sino que se requieren para contar con soluciones de calidad.

Llegado Chile a su Bicentenario, esta situación precisa revertirse, y ello no es solo tarea de los entes públicos, sino de la academia, los profesionales y el público.

En efecto, se están discutiendo proyectos de ley de relevancia científica y tecnológica en el Congreso Nacional, tan disímiles como la ley de derechos de los pacientes, la ley corta de Isapres II, la ley de TV digital, la normativa sobre transgénicos y sobre energía. En ellos el trabajo no puede solo radicar en la discusión política y la interrogación a sus autores, es necesario que el legislador demande la participación y colaboración de los expertos en estas materias, a fin que el resultado de estos trámites sea la dictación de una ley capaz de resistir a los tiempos, que se compadezca de realidades complejas, que tenga una visión efectiva de la realidad y que sirva auténticamente a las personas. 
Otro tanto tiene que suceder en nuestros tribunales: más allá del recurso de la prueba pericial, es indispensable, como lo ha considerado la Academia Judicial, la preparación de los jueces en múltiples materias, muchas de las cuales implican conocimientos de Biotecnología, Ecología, Genética, Física y otras tantas disciplinas que intervienen en las decisiones y que, muchas veces, son capaces de ser consultadas paras determinar el verdadero sentido y alcance de una norma.

La Revista Chilena de Derecho, comprometida con la investigación y con el avance del Derecho en este campo, propicia la publicación de artículos de frontera y, en esta oportunidad, convoca a un concurso especial destinado a fomentar la producción de literatura en tres áreas del Derecho altamente competentes para interrelacionarse con otras ciencias: el Derecho Penal, el Derecho Comercial y el Derecho Internacional. Así, adicionalmente al ser un vehículo de la difusión de la producción jurídica en Chile, queremos hacer una contribución a impulsar la producción jurídica que reafirma el Derecho como ciencia y ubica a esta en el ámbito del intercambio y de la retroalimentación con otros saberes igualmente puestos al servicio de la persona.

ÁngELA Vivanco MaRTínez

Directora

Revista Chilena de Derecho 